\title{
A comparison of in-service teachers' conceptions of barriers to mobile technology-integrated instruction and technology- integrated instruction
}

\author{
Chih-Hung Chen \\ National Taichung University of Education \\ Morris Siu-Yung Jong \\ The Chinese University of Hong Kong \\ Chin-Chung Tsai \\ National Taiwan Normal University
}

\begin{abstract}
Researchers have identified three orders of barriers to probe teachers' conceptions of technology-integrated instruction, namely extrinsic obstacles, intrinsic obstacles and the lack of design thinking. However, few studies have investigated barriers to teachers' mobile technology-integrated instruction and compared them with the barriers to their technologyintegrated instruction. This study recruited 20 in-service teachers with experience in adopting mobile learning (in practice) to compare their conceptions of the two kinds of barriers. Firstly, we utilised the phenomenographic method and subsequently transformed qualitative interview data into quantitative data. The research results found an additional crucial barrier, namely classroom management. Thus, this study revealed four classifications of barriers to (mobile) technology-integrated instruction. Moreover, teachers with less experience in adopting mobile learning confronted more obstructions to mobile technology-integrated instruction than to technology-integrated instruction at the first-order level (i.e., extrinsic obstacles). On the contrary, teachers with more experience in adopting mobile learning encountered more barriers related to design thinking upon the educational integration of mobile technology over conventional technology. This study provides the field with new insights into understanding teachers' conceptions of barriers to the adoption of emerging technology-integrated instruction and sheds light for researchers and policymakers who are working on teacher professional development.
\end{abstract}

\section{Implications for practice or policy:}

- This research reveals a framework of the four orders of barriers for providing an understanding of teachers' barriers to advanced technology-integrated instruction as the technology grows.

- More courses involving design thinking for mobile learning should be provided as part of teacher training.

- Future research should carefully explore the effective solutions for eliminating the barriers to mobile technology-integrated instruction.

Keywords: computer-assisted learning, learning technology, teachers' conceptions, mobile learning, barriers

\section{Introduction}

\section{Teachers' conceptions of technology-integrated instruction}

Studies have paid attention to teachers' conceptions of teaching (Biesta et al., 2015). The conception of teaching refers to a coherent system of the beliefs and personal epistemologies held by teachers about their views on experiencing teaching (M. Chen, Chai, et al., 2021; Teo \& Zhou, 2017). Teachers' conceptions of instruction can be classified into several categories: teacher-centred, student-centred, traditional or constructivist. Several studies have claimed the potential relationship between teachers' conceptions of teaching and ways of teaching and the crucial effects of their teaching conceptions on students' learning (Cheng et al., 2016; Taylor \& Booth, 2015), highlighting the importance of probing teachers' conceptions of teaching. 
With the continuous advances in information and communication technology (ICT), the way to integrate technology into education is changing. Several studies have asserted that teachers' adoption of technology in education is affected by their beliefs about technology (Burke et al., 2018; Wachira \& Keengwe, 2011), indicating the significance of exploring teachers' conceptions of technology integration. Technologyintegrated instruction refers to a teaching method incorporating appropriate technology into the contexts of teaching and learning in order to promote students' learning effectiveness (Al-Senaidi et al., 2009). Some educational researchers have investigated the influence of technology integration on education, such as students' learning achievement, learning attitudes, as well as high-order thinking (e.g., Sezer \& Sezer, 2019; Yen, 2020). Furthermore, some studies have highlighted the potential advantages of technology-integrated instruction to promote personalisation (X. Chen, Zou, et al., 2021) and engagement and to facilitate evaluation and prediction (X. Chen et al., 2020; Hwang et al., 2020). The more teachers attain ability in ICT integration, the faster the change in pedagogy (Jung, 2005). Thus, they can use technology more efficiently in the classroom and design better teaching (Uluyol \& Şahin, 2016). Teachers are expected to not only master the use of educational technology but also to engage in pedagogical design, such as the design of online learning content and mobile applications (Engeness, 2021).

\section{Factors regarding teachers' barriers to technology-integrated instruction}

Another aspect of technology-integrated instruction has attracted researchers' attention, that is, barriers to adopting technology for teaching. Barriers to technology integration are an important factor of teachers' willingness to utilise technology in their classrooms (Blackwell et al., 2013). While integrating technology into the classroom, teachers may encounter various kinds of barriers, and this could lead to different teaching outcomes (Ertmer, 1999). Teachers' adoption of technology for instruction is related to the degree to which they confront the barriers (Klein et al., 2019).

Ertmer (1999) categorised barriers to technology integration into first-order and second-order barriers. First-order barriers are extrinsic obstacles for teachers, involving lack of equipment, lack of time to plan instruction, technical problems and organisational support; on the contrary, second-order barriers are intrinsic obstacles for teachers, such as beliefs about technology, beliefs about teaching, lack of confidence and openness to change (Prestridge, 2012). Researchers have investigated two types of teachers' conceptions of barriers to adopting technology-integrated instruction in diverse educational stages, such as early childhood (Blackwell et al., 2013), elementary school (Kopcha, 2012), secondary school (Wood et al., 2005) and college (Pape \& Prosser, 2018) and have explored the origins of these barriers.

Furthermore, Tsai and Chai (2012) illustrated one more barrier: lack of design thinking. They regarded design thinking as the tendency to be connected with justified true beliefs, which moves dynamic creation of knowledge into the design style of knowing. Design thinking is an interdisciplinary field that adopts tools, methods, and thinking skills to generate better ideas for solving complex problems in practice (Primus \& Sonnenburg, 2018). As a result, it refers to the thinking skills or cognitive processes of creating new artefacts in a human-centred way and could be acquired via the individual's practice and experience. Moreover, several studies have declared that design thinking can offer teachers required skills for the creative challenge. For example, according to Henriksen et al. (2017), design thinking can provide teachers with scaffolding for creatively handling educational problems of practice via a flexible, accessible structure. This suggests the necessity of probing design thinking abilities in teacher education via specific tools, methods and theory. With the assistance of technology, design thinking facilitates knowledge creation via the process record of the development of new ideas, describing the significance of the teaching design of new educational technology for building understanding (Mishra \& Koehler, 2006). Moreover, according to the dynamic nature of the classroom context, teachers need design thinking to be innovative in learning materials, pedagogy, curricula and assessment in different contexts (Burdick \& Willis, 2011). Tsai and Chai considered the lack of design thinking, which strives to enhance current teaching and to create what is desired, by teachers as third-order barriers to technology-integrated instruction.

While conducting technology-integrated instruction, teachers may perceive some degree of barriers and their experience of those barriers has a huge influence on their decisions regarding the adoption of technology in school (Kopcha, 2012). It is worth noting that teachers may not be confronted with all of these kinds of barriers; any one of them alone can hinder meaningful integration of technology into their instruction (Ertmer, 1999). Therefore, it is worth conducting a detailed investigation into teachers' 
conceptions of barriers to advanced technology-integrated instruction as the technology grows and to explore effective ways to overcome the barriers.

\section{Ways to overcome teachers' barriers to technology-integrated instruction}

To overcome first-order barriers, researchers have suggested institutions to improve resources (e.g., hardware, software, and planning time) (Glogger-Frey et al., 2015) and enhance teachers' technical competence (Uluyol \& Şahin, 2016). Furthermore, Goktas et al. (2013) surveyed 1,373 Turkish primary school teachers with regard to their conceptions of the barriers to integrating technology into instruction and found that they considered "allocation of more budget and specific units for teachers or peer support" and "high quality training for ICT in pre-service teacher education" (p. 1) to be the most effective enablers.

Some studies have focused on eliminating second-order barriers by means of developing pedagogical models of technology integration or enhancing skills of pedagogical practices (Ertmer, 1999). For example, Wachira and Keengwe (2011) surveyed the relationships between teachers' beliefs about technology and their decisions regarding how to conduct technology-integrated instruction. Teachers' technological pedagogical content knowledge (TPACK) has been utilised in the quest for better instruction (Tseng et al., 2016), and researchers have regarded it as being a solution to the technology integration issue (e.g., Klein et al., 2019; Tsai \& Chai, 2012). To a certain degree, a teacher with stronger TPACK competence can settle the technology integration issue from a knowledge perspective (Tsai \& Chai, 2012). Although many barriers impede teachers' knowledge of practice or hinder them from carrying out their beliefs, intrinsic obstacles to teachers' technology integration could be removed by providing practical training activities, collaborative learning or activities to assist in changing their beliefs (Unger \& Tracey, 2013).

In a classroom, students and contexts are so dynamic that the teacher needs to exert their design thinking to synthesise learning materials or to create adequate learning activities (Tsai \& Chai, 2012). However, teachers' skills in problem-solving and innovation in practice may not only depend on their teaching experience; thus, more educational training, support and scaffolding are required for engaging them in design thinking practice (Burdick \& Willis, 2011; Henriksen et al., 2017). Furthermore, due to rapid advances in technology, knowledge of the latest hardware, software and terminology may be outmoded in a few years (Mishra \& Koehler, 2006). Thus, it is crucial for teachers to cultivate design capacity for different technology-integrated instruction, such as mobile technology.

\section{Trends and gaps in mobile technology-integrated instruction}

Owing to the rapid advancements in communication and mobile technology (e.g., personal digital assistants, smartphones or tablet computers), researchers have adopted mobile technology in education to facilitate learning, anytime and anywhere (Chin \& Wang, 2021; Hwang \& Fu, 2019). Researchers have used a number of terms to refer to instruction via mobile technology integration, such as mobile technologyintegrated instruction, mobile technology-assisted instruction (C. H. Chen \& Tsai, 2021), mobile technology-enhanced instruction (Hwang \& Wu, 2014), mobile technology-supported instruction (Jong et al., 2018) or mobile learning (Kearney \& Maher, 2019). Mobile technology-integrated instruction refers to a more specific concept of using mobile technologies in education. Researchers have proposed different perspectives on mobile technology-integrated instruction, such as learning by taking advantage of mobile technologies (Hwang \& Wu, 2014), anywhere anytime learning (Laine et al., 2010) and learning mobility (Baran, 2014). In this study, we use the term mobile technology-integrated instruction to more neutrally represent the aforementioned idea, since mobile technology-integrated instruction does not necessarily produce positive outcomes in learning. For example, in a review paper, Chee et al. (2017) found that some studies using mobile technology-integrated instruction may also have negative effects on students' learning. Nevertheless, some studies have illustrated the benefits of using mobile technology-integrated instruction, such as the affordance of authentic learning activities, inquiry learning experience, timely learning guidance and enhancement of students' engagement, learning and higher order thinking skills (C. H. Chen, 2020; Li $\&$ Wong, 2020). Furthermore, several review studies on mobile technology-integrated instruction have found that the major part of the papers addressed issues of te system designs for mobile learning or students' learning effectiveness (e.g., Hwang \& Fu, 2020; Liu et al., 2021). Thus, few studies have investigated teachers' conceptions of teaching in the context of mobile technology-integrated instruction. Hsieh and Tsai (2017) interviewed 15 teachers and revealed six qualitatively different conceptions, namely "meeting students' preferences", "conducting classes with efficiency", "invigorating and enhancing learning", 
"parting from traditional teaching", "focusing on student ownership" and "extending learning beyond school" (p. 82). Another example is C. H. Chen and Tsai's (2021) study, which adopted a phenomenographic approach to investigate in-service teachers' conceptions of mobile technologyintegrated instruction and revealed seven qualitatively different conceptions. This hierarchy portrayed a trajectory from teacher- or content-oriented to learner- or learning-oriented conceptions and described that mobile technology provides opportunities to enhance student-centred learning.

Rapid progress in computer and mobile technology constantly changes the kinds of environmental barriers to teachers' technology-integrated instruction (Jong \& Tsai, 2016; Mueller et al., 2008). Although the character of the barriers may change, investigation of some of the previous barriers remains worthwhile (Wood et al., 2005). Barriers to technology-integrated instruction, such as fear of change, lack of resources and lack of training, also obstruct the integration of mobile technology into the classroom (O'Bannon \& Thomas, 2014). Moreover, Looi et al. (2015) proposed that lack of exemplification of pedagogical designs is still the major gap in mobile learning. Up to now, far too little attention has been paid to in-service teachers' conceptions of the barriers to mobile technology-integrated instruction. Thus, probing teachers' conceptions of the barriers to mobile technology-integrated instruction and comparing them with those to their technology-integrated instruction is a significant issue for instructors or researchers.

\section{Purpose of the study}

Although a large number of classrooms have been well-equipped with technology, many teachers still perceive themselves as being ill-prepared for sufficient adoption of technology to transform instruction (Livingston \& Flores, 2017). The decision to adopt technological instruction is complex and influenced by a variety of factors (Klein et al., 2019). In recent decades, mobile devices have been referred to as an effective learning tool when used with teaching applications and mobile learning has become increasingly popular in elementary schools (Hwang \& Fu, 2019). Investigating what conceptions elementary teachers have of instruction and the barriers they face is essential for providing them with professional training and support (Hammack \& Ivey, 2019). Furthermore, Louws et al. (2017) foresaw that teachers with different experiences of teaching may differ in what they would like to learn and how. A thorough investigation into teachers' conceptions of the barriers to mobile technology-integrated instruction is therefore needed, since integrating appropriate pedagogical strategies with mobile technology for enhanced learning effectiveness has been a significant issue (Looi et al., 2015).

Thus, this study explored teachers' conceptions of the barriers to mobile technology-integrated instruction and compared them with those to conventional technology-integrated instruction by means of a mixedmethods approach for analysing participants' different conceptions of the barriers. In view of what has been mentioned so far, 20 elementary school teachers were interviewed. The research questions were:

(1) What are the categories of barriers to technology-integrated instruction and those to mobile technology-integrated instruction revealed by the teachers?

(2) What are the differences between teachers' conceptions of barriers to technology-integrated instruction and barriers to mobile technology-integrated instruction?

(3) What are the associations between teachers' conceptions of barriers to technology-integrated instruction and barriers to mobile technology-integrated instruction?

\section{Method}

\section{Participants}

A total of 20 elementary school teachers participated in individual interviews. All participants ( 2 males and 18 females) were from two elementary schools in Taipei, Taiwan. The participants conducted mobile technology-integrated instruction in diverse courses, such as Mandarin, English, Mathematics, Science and Technology, Social Studies, Arts and Humanities, and Integrative Activities. Their ages ranged from 25 to $55(M=42.6)$, while the number of years of their teaching experience, technology-integrated teaching experience and mobile technology-integrated teaching experience ranged from 2 to $28(M=15.8), 2$ to 15 $(M=12.1)$ and 1 to $15(M=3.85)$ years respectively. Given such diverse backgrounds, the sample can, to a certain extent, provide an opportunity to shed light on how experienced teachers think about integrating mobile technology into their classrooms. The participants were selected based on their having more than 1 
year of experience in conducting courses supported by mobile technology-integrated instruction, with every student equipped with a tablet during school time. Moreover, each school provides a mobile-learning platform with some specific functions related to mobile learning, such as timely feedback and digital records for learning anytime and anywhere. The participants were protected by hiding their individual information. They knew that participation was voluntary and that they could quit at any time.

\section{Data collection from the interviews}

In 2016, one of us (C.-H. C.) conducted individual semi-structured interviews with each teacher. The interviews were not limited in time and took approximately 30-40 minutes. The guiding interview items for evaluating the teachers' conceptions regarding the barriers to technology-integrated instruction were designed based on the studies by Trigwell et al. (1994) and Tsai (2009), as shown below:

- Was there anything about technology-integrated teaching that you found difficult?

- Could you describe what an ideal teaching environment would look like? Why?

The interview items for exploring the teachers' conceptions regarding the barriers to mobile technologyintegrated instruction were similar to those of technology-integrated instruction, as presented below:

- Was there anything about teaching via mobile learning that you found difficult?

- Could you describe what an ideal mobile teaching environment would look like? Why?

All of the interviews were carried out in Chinese, the teachers' mother tongue. Every interview was audiorecorded and then fully transcribed by two of us (C.-H. C. \& C.-C. T.). The verbatim transcripts of the teacher interviews were analysed to probe their conceptions of technology-integrated instruction and mobile technology-integrated instruction.

\section{Data analysis of the interviews}

The verbatim transcripts of the teacher interviews were analysed by means of the phenomenographic method, as described by Marton (1981). The phenomenographic method is a kind of qualitative methodology, combining interviews, protocol and conversation, for analysing participants' hierarchically related issues of interest (Richardson, 1999). By way of classification of the descriptions of the phenomena experienced, the structural constitution of the means is presented (C. H. Chen \& Tsai, 2021). Some critical sentences and keywords about teachers' views were carefully selected. Subsequently, the differences and similarities of the sentences and keywords in the teachers' interviews related to their technology-integrated instruction and mobile technology-integrated instruction were extracted. Therefore, some qualitatively different classifications of description of the barriers of teachers' (mobile) technology-integrated instruction were generated via the differences and similarities in the teachers' main ideas. Overall, the phenomenographic analysis performed in this study was used to generalise some classifications of descriptions with characteristics of qualitatively different ideas about the barriers to teachers' (mobile) technology-integrated instruction.

Two of us (C.-H. C. \& C.-C. T.) independently categorised all the verbatim transcripts into classifications of barriers. The percentage of agreement concerning the barriers to technology-integrated instruction and those to mobile technology-integrated instruction was calculated to demonstrate the intercoder reliability, indicating that the agreement was $88 \%$ and $82 \%$, respectively.

\section{Results}

\section{Categories of barriers to technology-integrated instruction and those to mobile technology-integrated instruction}

Even though the features of the barriers may change as the technology developed, several studies (e.g., Kopcha, 2012; Pape \& Prosser, 2018; Tsai \& Chai, 2012) provided good references for probing teachers' conceptions of barriers (e.g., extrinsic obstacles, intrinsic obstacles and the lack of design thinking) to (mobile) technology-integrated instruction. Interestingly, according to the teachers in this study, classroom 
management plays a crucial role in (mobile) technology-integrated instruction. Many of the teachers considered classroom management to be a significant barrier when using technology in their classrooms. Thus, we regarded classroom management as another significant barrier to (mobile) technology-integrated instruction. This view is consistent with the description expressed by Ertmer (1999), that classroom management problems may happen as a result of teachers' preference for the control of students' learning. For example, in this study, a teacher illustrated her conceptions of barriers to mobile technology-integrated instruction as follows:

During the learning activity, some students did not always concentrate on the course; they used another app on the mobile device instead. They minimised the designated app and used another app for music or movies.

Classroom management can be a higher order barrier for technology integration than teachers' personal beliefs. Although a teacher has the willingness to change, classroom management problems may still occur. Accordingly, in this study, we proposed four classifications of the barriers to (mobile) technologyintegrated instruction as hierarchical categories, namely extrinsic obstacles, intrinsic obstacles, classroom management and the lack of design thinking (as shown in Table 1), based on several frameworks (e.g., Ertmer, 1999; Tsai \& Chai, 2012).

Table 1

Framework of the four orders of barriers to (mobile) technology-integrated instruction

\begin{tabular}{|c|c|c|c|}
\hline Level & Definition & $\begin{array}{l}\text { Examples of barriers to } \\
\text { technology-integrated } \\
\text { instruction }\end{array}$ & $\begin{array}{l}\text { Examples of barriers to mobile } \\
\text { technology-integrated } \\
\text { instruction }\end{array}$ \\
\hline First order & $\begin{array}{l}\text { Extrinsic obstacles for } \\
\text { teachers, including } \\
\text { lack of equipment, } \\
\text { technical problems } \\
\text { and organisational } \\
\text { support }\end{array}$ & $\begin{array}{l}\text { In conventional } \\
\text { classrooms, recorders are } \\
\text { always insufficient. } \\
\text { Students cannot easily } \\
\text { modify their pronunciation } \\
\text { through listening to their } \\
\text { own voices. }\end{array}$ & $\begin{array}{l}\text { The apps may not work } \\
\text { reliably on older mobile } \\
\text { devices. It is difficult for me to } \\
\text { teach if the mobile device or } \\
\text { other equipment does not work } \\
\text { reliably. }\end{array}$ \\
\hline Second order & $\begin{array}{l}\text { Intrinsic obstacles for } \\
\text { teachers, such as } \\
\text { beliefs about teaching } \\
\text { and technology, and } \\
\text { openness to change }\end{array}$ & $\begin{array}{l}\text { I cannot be sure of the } \\
\text { learning situation of every } \\
\text { student or how well they } \\
\text { understand the learning } \\
\text { conceptions. }\end{array}$ & $\begin{array}{l}\text { I think that mobile devices are } \\
\text { still a pure tool for facilitating } \\
\text { students' learning. I need to } \\
\text { learn how to effectively take } \\
\text { advantage of a mobile device } \\
\text { rather than be restricted by it. }\end{array}$ \\
\hline Third order & $\begin{array}{l}\text { Barriers to classroom } \\
\text { management }\end{array}$ & $\begin{array}{l}\text { It is difficult to master the } \\
\text { students' engagement. } \\
\text { Although students } \\
\text { sometimes looked at the } \\
\text { teacher, they did not pay } \\
\text { attention to what the } \\
\text { teacher did. }\end{array}$ & $\begin{array}{l}\text { A student may be attracted to } \\
\text { the mobile device. Other apps } \\
\text { on the device may sometimes } \\
\text { distract his attention from his } \\
\text { learning. I need to remind him } \\
\text { to focus on the study. There is } \\
\text { a lot of content on the mobile } \\
\text { device, and some interesting } \\
\text { matters could be triggered via } \\
\text { the button or some other } \\
\text { means. }\end{array}$ \\
\hline Fourth order & $\begin{array}{l}\text { Lack of design } \\
\text { thinking }\end{array}$ & & $\begin{array}{l}\text { If the course is well-designed, } \\
\text { students can be immersed in } \\
\text { the learning process. It is a } \\
\text { challenge for me to adopt } \\
\text { adequate mobile technology at } \\
\text { the right time and in the right } \\
\text { place to improve students' } \\
\text { learning effectiveness. }\end{array}$ \\
\hline
\end{tabular}


Teachers may confront various different order barriers while conducting technology-integrated instruction. Moreover, many of the barriers mentioned by the teachers in this study were present in previous studies (e.g., Ertmer, 1999; Tsai \& Chai, 2012), but some were less mentioned. It is worth exploring the variety of the barriers to teachers' technology-integrated instruction as time goes by. Table 2 presents the distribution of the barriers to technology-integrated instruction illustrated by the teachers. Among the 20 elementary school teachers, eight (40\%) expressed only one level of barriers to technology-integrated instruction, while the others $(60 \%)$ encountered multiple barriers that constrained their technology integration.

Table 2

Teachers' conceptions of the barriers to technology-integrated instruction

\begin{tabular}{ll}
\hline Categories & No. \\
\hline Second order & 6 \\
Third order & 2 \\
First order, second order & 4 \\
First order, third order & 4 \\
Second order, third order & 3 \\
First order, second order, third order & 1 \\
\hline
\end{tabular}

As shown in Table 3, seven (35\%) among the 20 elementary school teachers demonstrated only one level of barrier to mobile technology-integrated instruction in their interview transcriptions. The others met more than one category when integrating technologies into education. Specifically, three teachers illustrated all four levels of barriers.

Table 3

Teachers' conceptions of the barriers to mobile technology-integrated instruction

\begin{tabular}{ll}
\hline Categories & No. \\
\hline First order & 5 \\
Second order & 1 \\
Third order & 1 \\
First order, third order & 3 \\
First order, fourth order & 1 \\
Third order, fourth order & 1 \\
First order, second order, third order & 3 \\
First order, second order, fourth order & 1 \\
First order, third order, fourth order & 1 \\
First order, second order, third order, fourth order & 3 \\
\hline
\end{tabular}

\section{Differences between the barriers to technology-integrated instruction and mobile technology-integrated instruction}

Human conceptions are mixed and overlapping (C. H. Chen \& Tsai, 2021; Kember, 1997). This implies that clearly representing teachers' conceptions is difficult. To further analyse and reveal teachers' conceptions of barriers to technology-integrated instruction, their interview results were presented by way of "main" and "achieved" levels, as utilised by Tsai (2009) and Yang and Tsai (2010). In this study, the "main" level idea was applied to depict predominant conceptions of the barriers to (mobile) technologyintegrated instruction as described by the teachers, while the "achieved" level represented the highest order classification of teachers' barriers to (mobile) technology-integrated instruction.

For example, a teacher described her conception of the barriers to mobile technology-integrated instruction as follows:

It is a problem to connect mobile devices with a wireless LAN network when teaching outdoors. On the other hand, in the classroom, my teaching was sometimes interrupted due to the app or mobile signal strength, but I had no idea what to do. Moreover, the apps may not work reliably. With regard to teacher preparation, it takes a great deal more time on the course design. (Teacher A) 
According to the interview quote above, the main conception of the teacher related to software, hardware and information literacy, which is categorised as first-order barriers. Her "main" level idea of barriers to mobile technology-integrated instruction belongs to the first-order barriers (see Table 1). Furthermore, only one idea about course design - a fourth-order level barrier - was revealed. As expressed in Tsai and Chai's (2012) study, the lack of design thinking by teachers is a higher order category of barriers to technologyintegrated instruction than the lack of adequate access and institutional support; thus, her "achieved" level barrier of mobile technology-integrated instruction was classified as fourth-order level.

By way of illustration, Tsai (2009) asserted that personal conceptions can be differentiated more finely with the analysis of the "achieved" conceptions, especially for the same category of personal "main" conceptions, but with subtle differences. Several studies on the barriers of technology-integrated instruction have described that a teacher may confront several different-order barriers when integrating technologies into education (e.g., van Praag \& Sanchez, 2015; Wang et al., 2014). The approach of "main" and "achieved" conceptions may be a meaningful way to analyse teachers' barriers to (mobile) technologyintegrated instruction, including various different-order levels.

For instance, one of the three teachers with barriers across the first and third orders (Table 3) illustrated her conceptions of barriers to mobile technology-integrated instruction as follows:

I am confused about the breakdown of the mobile device or a slow Internet connection. Students were very excited about mobile learning in the beginning. Once they got mobile devices, they were very happy. They considered them as toys; however, their interest in the devices declined after finding that they were learning tools. Moreover, online games may distract students from their learning. (Teacher B)

Another teacher with barriers across the first and third orders (Table 3) described her conceptions of barriers to mobile technology-integrated instruction as below:

It took more time to familiarise the students with the operation of the mobile device and software. Furthermore, students' information literacy needs to be enhanced when conducting mobile learning. During the mobile learning activity, it should be confirmed that the students were performing adequate operations. (Teacher $\mathrm{C}$ )

Teacher B was categorised as expressing third-order barriers for her "main" conceptions of mobile technology-integrated instruction and Teacher $\mathrm{C}$ referred to first-order barriers. On the other hand, the "achieved" conceptions of both teachers were considered to be third-order barriers, describing the teachers" potential conceptions of the barriers. Thus, the utilisation of the "main" and "achieved" levels can attain a clearer profile of the teachers' conceptions of the barriers and the results can thus be conveniently analysed. Furthermore, with regard to technology-integrated instruction, a teacher illustrated her ideas as follows:

When posing a question, I was not sure whether the students exactly understood the meaning of that question. I thought that teachers could not clearly grasp each student's learning situation in the classroom. Moreover, some students always just listen to their peers without discussion in a collaborative learning environment. (Teacher D)

According to the framework of the four-order barriers of technology-integrated instruction, the teacher's "main" ideas and their "achieved" ideas of technology-integrated instruction were labelled as second-order barriers and third-order barriers respectively.

The descriptive statistics of teachers" "main" conceptions of the barriers to technology-integrated instruction and mobile technology-integrated instruction are shown in Table 4. Among the 20 teachers, three, 10 and seven conveyed their "main" conceptions of the barriers to technology-integrated instruction at the first-, second- and third-order levels respectively. Moreover, none of the teachers mentioned any fourth-order barriers regarding design thinking. On the other hand, the levels of the teachers" "main" conceptions of barriers to mobile technology-integrated instruction were eight, four, six and two in ascending order respectively. It is worth noting that eight teachers (40\%) indicated their "main" conceptions of the barriers at the first-order level. Moreover, the levels of teachers" "main" conceptions 
about the barriers to mobile technology-integrated instruction trend slightly upwards according to their experience in adopting mobile learning.

To further explore the possible differences between the "main" conceptions of barriers to technologyintegrated instruction and those of mobile technology-integrated instruction, a chi-square analysis was conducted in this study. A significant difference was proven with $x^{2}=7.86(p<0.05)$, implying that the distribution of teachers' "main" conceptions of the barriers to technology-integrated instruction were significantly different from those of mobile technology-integrated instruction. Moreover, a post hoc test was utilised to recognise which levels of the teachers' conceptions about the two kinds of barriers were significantly different. The analytical results showed that only a significant difference between the two kinds of barriers was confirmed for the second-order barriers. Therefore, the teachers expressed that they suffered more intrinsic obstacles to technology-integrated instruction than those to mobile technologyintegrated instruction, indicating the significant dissimilarity in teachers' conceptions of the barriers to the two kinds of technology-integrated instruction.

Table 4

Teachers' "main" ideas of the barriers to technology-integrated instruction and mobile technologyintegrated instruction $(N=20)$

\begin{tabular}{lccc}
\hline Order & $\begin{array}{c}\text { Barriers to technology- } \\
\text { integrated instruction: no. } \\
(\%)\end{array}$ & $\begin{array}{c}\text { Barriers to mobile } \\
\text { technology-integrated } \\
\text { instruction: no. }(\%)\end{array}$ & $\begin{array}{c}\text { Experience in adopting } \\
\text { mobile learning: } \\
\text { years }\end{array}$ \\
\hline First order & $3(15 \%)$ & $8(40 \%)$ & 3.63 \\
Second order & $10(50 \%)$ & $4(20 \%)$ & 3.00 \\
Third order & $7(35 \%)$ & $6(30 \%)$ & 4.17 \\
Fourth order & $0(0 \%)$ & $2(10 \%)$ & 5.50 \\
\hline
\end{tabular}

$x^{2}(3, n=40)=7.86, p<0.05$

With respect to the teachers" "achieved" conceptions of the barriers, Table 5 portrays the distribution of their conceptions of the barriers to (mobile) technology-integrated instruction. Based on their statements, teachers' "achieved" conceptions of the barriers to technology-integrated instruction were labelled as neither first order nor fourth order. Ten teachers' "achieved" conceptions of the barriers to technologyintegrated instruction reached the second order, while the other 10 teachers reached the third order. With regard to teachers" "achieved" conceptions of the barriers of mobile technology-integrated instruction, five, one, seven and seven teachers were categorised into the first-, second-, third- and fourth-order levels respectively. The majority of the teachers' "achieved" conceptions of the barriers to integrating mobile technologies into education belonged to higher order levels, such as the third- and fourth- order barriers. Furthermore, the more years teachers had experience in adopting mobile learning, the closer they were to reaching higher order levels of "achieved" conceptions of the barriers.

In this study, a chi-square analysis was conducted for evaluating the possible differences between the "achieved" conceptions of barriers to technology-integrated instruction and those to mobile technologyintegrated instruction described by the teachers. A significant difference was confirmed $\left(x^{2}=25.72, p<\right.$ 0.001 ), indicating that the "achieved" conceptions of the barriers to technology-integrated instruction expressed by the teachers were significantly different from those of mobile technology-integrated instruction.

Table 5

Teachers' "achieved" ideas of the barriers to technology-integrated instruction and mobile technologyintegrated instruction $(N=20)$

\begin{tabular}{lccc}
\hline Order & $\begin{array}{c}\text { Barriers to technology- } \\
\text { integrated instruction: no. }(\%)\end{array}$ & $\begin{array}{c}\text { Barriers to mobile } \\
\text { technology-integrated } \\
\text { instruction: no. }(\%)\end{array}$ & $\begin{array}{c}\text { Experience in adopting } \\
\text { mobile learning: (years) }\end{array}$ \\
\hline First order & $0(0 \%)$ & $5(25 \%)$ & 1.60 \\
Second order & $10(50 \%)$ & $1(5 \%)$ & 3.00 \\
Third order & $10(50 \%)$ & $7(35 \%)$ & 4.71 \\
Fourth order & $0(0 \%)$ & $7(35 \%)$ & 4.71 \\
\hline
\end{tabular}

$x^{2}(3, n=40)=25.72, p<0.001$ 
To further investigate the possible differences in the four order levels of the barriers to the two kinds of technology-integrated instruction, a post hoc test was adopted, with the result showing that significant differences were found at the first-, second- and fourth-order levels. The teachers illustrated more firstorder obstacles to mobile technology-integrated instruction than to technology-integrated instruction. In the interviews, in general, they stated that mobile technologies are likely to suffer from interrupted service and that they cannot find out what the problem is. The "achieved" conceptions of the first-order barriers occurred frequently to those teachers with less experience in adopting mobile learning ( $M=1.6$ years). The teachers' conceptions of the barriers which achieved the second-order level are also quite different. The teachers described their barriers to integrating technologies into education, while only one stated the impediment to conducting mobile technology-assisted instruction. Conventional technologies cannot satisfy some of the interviewed teachers who want to urgently address the students' learning situation. On the contrary, most of them considered that mobile technologies have the advantage of adaptive teaching by means of instant feedback and prompts, which conventional technologies lack. Most teachers also presented high willingness to change learning contexts. According to the results of the interviews, teachers who engaged in mobile learning had strong beliefs about mobile technology-integrated instruction, implying their abilities to conquer the second-order barriers. Furthermore, a significant difference was confirmed in the fourth-order barriers of the two kinds of technology-integrated instruction. None of the interviewed teachers mentioned design thinking in relation to technology-integrated instruction, whereas $35 \%$ spent a great amount of time designing courses for mobile learning.

\section{Association between teachers' conceptions of barriers to technology-integrated instruction and barriers to mobile technology-integrated instruction}

In this study, the association between teachers' barriers to technology-integrated instruction and mobile technology-integrated instruction was investigated via the analysis of the conceptions of individual teachers. Table 6 describes all the combinations of individual teachers' conceptions of the barriers to (mobile) technology-integrated instruction. For example, two teachers' "main" conceptions of barriers to integrating technologies into education were categorised as the first-order level, whereas their "main" conceptions of barriers to mobile technology-integrated instruction were classed as the second-order level. The results in Table 6 present that nine among the 20 teachers held lower order conceptions of barriers to mobile technology-integrated instruction than to technology-integrated instruction. Most of them were confronted with first-order level barriers (eight teachers), especially problems of hardware and software. Five teachers expressed identical levels at the "main" conceptions of barriers to both kinds of technologyintegrated instruction. Furthermore, six teachers expressed their "main" conceptions of barriers to mobile technology-integrated instruction at a higher level than their conceptions of barriers to technologyintegrated instruction.

Table 6

Association between teachers' "main” ideas of barriers to technology-integrated instruction and mobile technology-integrated instruction $(N=20)$

\begin{tabular}{lcccc}
\hline BTII (Order) & \multicolumn{4}{c}{ BMTII (Order) } \\
& First order & Second order & Third order & Fourth order \\
\hline First order & & 2 & 1 & \\
Second order & 6 & 1 & 1 & 2 \\
Third order & 2 & 1 & 4 &
\end{tabular}

Fourth order

Note. BTII = barriers to technology-integrated instruction; BMTII = barriers to mobile technologyintegrated instruction.

A similar investigation into the association between teachers' "achieved" conceptions of technologyintegrated instruction and mobile technology-integrated instruction was executed in this study, as depicted in Table 7. Five teachers tended to have lower order conceptions of the barriers to mobile technologyintegrated instruction than to technology-integrated instruction, all of whom encountered obstacles of the first-order level in operating mobile technologies in the classroom. Five teachers revealed the same order of barriers to the two kinds of technology-integrated instruction. Ten teachers had higher order conceptions of the barriers to the mobile technology-integrated instruction and seven considered the design thinking in mobile learning as a barrier to integrating mobile technology into education. 
Table 7

Association between teachers' "achieved" ideas of technology-integrated instruction and mobile technology-integrated instruction $(N=20)$

\begin{tabular}{lcccc}
\hline BTII (Order) & & \multicolumn{2}{c}{ BMTII (Order) } \\
& First order & Second order & Third order & Fourth order \\
\hline First order & 3 & 1 & 3 & 3 \\
Second order & 2 & 4 & 4 \\
Third order & & & \\
Fourth order & & & \\
Note. BTII = barriers & to technology-integrated instruction; BMTII = barriers to mobile technology- \\
integrated instruction.
\end{tabular}

\section{Discussion and conclusions}

Research has illustrated that any kind of barrier can impede meaningful technology-integrated instruction, and the tendency to integrate technologies into the classroom is related to the degree of barriers that teachers face (Blackwell et al., 2013; Wachira \& Keengwe, 2011). This study revealed a framework of four classifications of barriers to (mobile) technology-integrated instruction, namely extrinsic obstacles, intrinsic obstacles, classroom management and the lack of design thinking. Among the four classifications, classroom management is regarded as a significant barrier to (mobile) technology-integrated instruction (Bingimlas, 2009), but has seldom been depicted in research. Furthermore, this study revealed that the teachers' conceptions of the barriers of mobile technology-integrated instruction were significantly different from those of technology-integrated instruction. This could be due to the differences between the concepts of the two types of technology integration. Technology-integrated instruction refers to a general concept of the use of technologies in education, while mobile technology-integrated instruction is regarded as a more specific concept of the utilisation of mobile technologies in education. Such a finding also corresponds to what has been proposed by Goktas et al. (2013), who illustrated that the kinds of impediments to teachers' technology-integrated instruction may change due to the development of the information technology.

With regard to the barriers to technology-integrated instruction, this study reveals that teachers' "achieved" conceptions of the barriers focused on the second- and third-order levels. None of the interviewed teachers' "achieved" conceptions of the barriers to technology-integrated instruction pertained to the first-order level. With advancements in ICT, educational technology is well developed, particularly in terms of the stability and reliability of the software and hardware (Huang \& Hwang, 2021). Moreover, technology-integrated instruction has been the focus of attention in Taiwan for decades (Chauhan, 2017). It is reasonable that fewer teachers confront the first-order level barriers of technology-integrated instruction. This is consistent with the assertion expressed by Mueller et al. (2008), who described that the obstruction to technology integration has shifted from the first-order level, such as hardware, software and technical issues, to higher order levels (i.e., individual and environmental factors). It also complies with Ertmer (1999), who asserted that teachers who have reached higher levels of technology use would confront fewer first-order barriers. However, there were no teachers' conceptions of the barriers to technology-integrated instruction which attained the fourth order, namely design thinking. This finding implies that the interviewed teachers did not consider the obstruction of design thinking when combining education with technology. This result may be related to the teachers' conceptions of the second-order barriers to technology-integrated instruction. They deemed that the conventional technology hardly satisfies the learning context nowadays, indicating the necessity of integrating advanced technology into education, such as mobile technology.

Unlike the distribution of the barriers for technology-integrated instruction, the teachers" "achieved" conceptions of the barriers of mobile technology-integrated instruction are almost evenly distributed over the first-, third- and fourth-order levels. One interesting finding is that the second-order barriers were barely mentioned, implying that teachers who engage in mobile learning have strong beliefs in mobile technologyintegrated instruction, and expressed their abilities to conquer the second-order barriers. Such a result corresponds to the description in several previous studies - some teachers, who have redefined teacher roles and embraced alternative teaching practices, would not confront second-order barriers (Ertmer, 1999). Studies have proven that mobile learning is of benefit to students' learning, for example, by providing authentic learning activities and leading to improvement in the students' higher order thinking skills (C. H. 
Chen, 2020; Jong et al., 2018; Li \& Wong, 2020). This finding also reinforces the significance of the integration of mobile technology into education.

Although mobile technology can afford opportunities for teachers to create new learning environments and conquer some barriers to technology-integrated instruction, different forms of barriers were generated with mobile educational technologies. For example, compared to the barriers to technology-integrated instruction, teachers were inclined to have lower order conceptions of the barriers to mobile technologyintegrated instruction on the first-order level. Moreover, the teachers in this study with less experience in adopting mobile learning frequently faced obstructions of the first-order level. This implies that teachers would confront obstacles of the first-order level in operating advanced technology, and they need more assistance to become skilled in the use of the new technology. Despite the view expressed by Prestridge (2012) that first-order barriers are being overcome, the teachers still confront impediments of new technology, such as mobile technology. To conquer these barriers, professional development activities are required in pre-service and in-service training (Goktas et al., 2013; Kopcha, 2012).

Mobile technology can not only facilitate students' learning at the right time and in the right place but also promote student-centred learning (C. H. Chen \& Tsai, 2021; Jong \& Tsai, 2016). A great number of professional and creative skills in teaching design are essential for mobile technology-integrated instruction; however, teachers with more experience in adopting mobile learning still encountered fourthorder barriers. More courses involving design thinking for mobile learning should be provided as part of teacher training.

Advanced technology can bring new opportunities for students' learning. This study analysed teachers' conceptions of the barriers to (mobile) technology-integrated instruction and compared the differences between their conceptions of the two kinds of technology-integrated instruction. Teachers with different experience of teaching would differ in their conceptions of teaching (Louws et al., 2017); this study further reveals the differences between the teachers' barriers to technology-integrated instruction and those to advanced technology-integrated instruction. The findings of this study make several contributions to the field. First, advanced technology may promote teachers' beliefs about technology-integrated instruction, so as to conquer the second-order barriers. Second, classroom management could be a usual barrier to technology-integrated instruction despite the technology advances. Third, teachers may face the first-order barriers when adopting new technology in the initial stages and perceive higher order barriers after gaining more technology-integrated teaching experience. Such findings provide an understanding of teachers' conceptions of barriers to advanced technology-integrated instruction and would be of interest to researchers or governments who engage in teacher professional development.

The small sample size is a limitation of this study. Large-scale data collection is suggested for future research. It is also worth exploring teachers' conceptions by adopting various technologies for instruction (such as mobile technology, digital games or virtual reality) and investigating possibly different types of barriers cross varying technologies.

\section{Acknowledgements}

This study is supported in part by the Ministry of Science and Technology of Taiwan under contract numbers MOST 109-2511-H-003-014-MY3 and MOST 108-2511-H-003-038-MY3. This work was financially supported by the Institute for Research Excellence in Learning Sciences of National Taiwan Normal University from The Featured Areas Research Centre Program within the framework of the Higher Education Sprout Project by the Ministry of Education in Taiwan.

\section{References}

Al-Senaidi, S., Lin, L., \& Poirot, J. (2009). Barriers to adopting technology for teaching and learning in Oman. Computers \& Education, 53(3), 575-590. https://doi.org/10.1016/j.compedu.2009.03.015

Baran, E. (2014). A review of research on mobile learning in teacher education. Educational Technology \& Society, 17(4), 17-32. https://drive.google.com/open?id=1TtsPlxZ99noxso1YdTR2VRRRJ9hqOuOD 
Biesta, G., Priestley, M., \& Robinson, S. (2015). The role of beliefs in teacher agency. Teachers and Teaching, 21(6), 624-640. https://doi.org/10.1080/13540602.2015.1044325

Bingimlas, K. A. (2009). Barriers to the successful integration of ICT in teaching and learning environments: A review of the literature. Eurasia Journal of Mathematics, Science and Technology Education, 5(3), 235-245. https://doi.org/10.12973/ejmste/75275

Blackwell, C. K., Lauricella, A. R., Wartella, E., Robb, M., \& Schomburg, R. (2013). Adoption and use of technology in early education: The interplay of extrinsic barriers and teacher attitudes. Computers \& Education, 69, 310-319. https://doi.org/10.1016/j.compedu.2013.07.024

Burdick, A., \& Willis, H. (2011). Digital learning, digital scholarship and design thinking. Design Studies, 32(6), 546-556. https://doi.org/10.1016/j.destud.2011.07.005

Burke, P. F., Schuck, S., Aubusson, P., Kearney, M., \& Frischknecht, B. (2018). Exploring teacher pedagogy, stages of concern and accessibility as determinants of technology adoption. Technology, Pedagogy and Education, 27(2), 149-163. https://doi.org/10.1080/1475939X.2017.1387602

Chauhan, S. (2017). A meta-analysis of the impact of technology on learning effectiveness of elementary students. Computers \& Education, 105, 14-30. https://doi.org/10.1016/j.compedu.2016.11.005

Chee, K. N., Yahaya, N., Ibrahim, N. H., \& Noor Hassan, M. (2017). Review of mobile learning trends 2010-2015: A meta-analysis. Educational Technology \& Society, 20(2), 113-126. https://drive.google.com/open?id=1dJvhFr8Ake3fRnXFFsB23zkMCSVZKvnj

Chen, C. H. (2020). Impacts of augmented reality and a digital game on students' science learning with reflection prompts in multimedia learning. Educational Technology Research and Development, 68(6), 3057-3076. https://doi.org/10.1007/s11423-020-09834-w

Chen, C. H., \& Tsai, C. C. (2021). In-service teachers' conceptions of mobile technology-integrated instruction: Tendency towards student-centred learning. Computers \& Education, 170, Article 104224. https://doi.org/10.1016/j.compedu.2021.104224

Chen, M., Chai, C. S., Jong, M. S. Y., \& Jiang, M. Y. C. (2021). Teachers' conceptions of teaching Chinese descriptive composition with interactive spherical video-based virtual reality. Frontiers in Psychology, 12, Article 591708. https://doi.org/10.3389/fpsyg.2021.591708

Chen, X., Xie, H., Zou, D., \& Hwang, G. J. (2020). Application and theory gaps during the rise of Artificial Intelligence in Education. Computers and Education: Artificial Intelligence, 1, Article 100002. https://doi.org/10.1016/j.caeai.2020.100002

Chen, X., Zou, D., Xie, H., \& Cheng, G. (2021). Twenty years of personalized language learning: Topic modeling and knowledge mapping. Educational Technology \& Society, 24(1), 205-222. https://drive.google.com/open?id=1dJvhFr8Ake3fRnXFFsB23zkMCSVZKvnj

Cheng, A. Y. N., Tang, S. Y. F., \& Cheng, M. M. H. (2016). Changing conceptions of teaching: A fouryear learning journey for student teachers. Teachers and Teaching, 22(2), 177-197. https://doi.org/10.1080/13540602.2015.1055437

Chin, K. Y., \& Wang, C. S. (2021). Effects of augmented reality technology in a mobile touring system on university students' learning performance and interest. Australasian Journal of Educational Technology, 37(1), 27-42. https://doi.org/10.14742/ajet.5841

Engeness, I. (2021). Developing teachers' digital identity: Towards the pedagogic design principles of digital environments to enhance students' learning in the 21st century. European Journal of Teacher Education, 44(1), 96-114. https://doi.org/10.1080/02619768.2020.1849129

Ertmer, P. A. (1999). Addressing first-and second-order barriers to change: Strategies for technology integration. Educational Technology Research and Development, 47(4), 47-61. https://doi.org/10.1007/BF02299597

Glogger-Frey, I., Kappich, J., Schwonke, R., Holzäpfel, L., Nückles, M., \& Renkl, A. (2015). Inventing motivates and prepares student teachers for computer-based learning. Journal of Computer Assisted Learning, 31(6), 546-561. https://doi.org/10.1111/jcal.12097

Goktas, Y., Gedik, N., \& Baydas, O. (2013). Enablers and barriers to the use of ICT in primary schools in Turkey: A comparative study of 2005-2011. Computers \& Education, 68, 211-222. https://doi.org/10.1016/j.compedu.2013.05.002

Hammack, R., \& Ivey, T. (2019). Elementary teachers' perceptions of K-5 engineering education and perceived barriers to implementation. Journal of Engineering Education, 108(4), 503-522. https://doi.org/10.1002/jee.20289

Henriksen, D., Richardson, C., \& Mehta, R. (2017). Design thinking: A creative approach to educational problems of practice. Thinking Skills and Creativity, 26, 140-153.

https://doi.org/10.1016/j.tsc.2017.10.001 
Hsieh, W. M., \& Tsai, C. C. (2017). Taiwanese high school teachers' conceptions of mobile learning. Computers \& Education, 115, 82-95. https://doi.org/10.1016/j.compedu.2017.07.013

Huang, H., \& Hwang, G. J. (2021). Advancement and research issues of ICT-based training for newly graduated nurses: A review of journal publications from 1985 to 2017. Interactive Learning Environments, 29(1), 164-178. https://doi.org/10.1080/10494820.2018.1559865

Hwang, G. J., \& Fu, Q. K. (2019). Trends in the research design and application of mobile language learning: A review of 2007-2016 publications in selected SSCI journals. Interactive Learning Environments, 27(4), 567-581. https://doi.org/10.1080/10494820.2018.1486861

Hwang, G. J., \& Fu, Q. K. (2020). Advancement and research trends of smart learning environments in the mobile era. International Journal of Mobile Learning and Organisation, 14(1), 114-129. https://doi.org/10.1504/IJMLO.2020.103911

Hwang, G. J., \& Wu, P. H. (2014). Applications, impacts and trends of mobile technology-enhanced learning: A review of 2008-2012 publications in selected SSCI journals. International Journal of Mobile Learning and Organisation, 8(2), 83-95. https://doi.org/10.1504/IJMLO.2014.062346

Hwang, G. J., Xie, H., Wah, B. W., \& Gašević, D. (2020). Vision, challenges, roles and research issues of Artificial Intelligence in Education. Computers and Education: Artificial Intelligence, 1, Article 100001. https://doi.org/10.1016/j.caeai.2020.100001

Jong, M. S. Y., Chan, T., Hue, M. T., \& Tam, V. (2018). Gamifying and mobilising social enquiry based learning in authentic outdoor environments. Educational Technology \& Society, 21(4), 277292. https://drive.google.com/open?id=1gud1XNADttZBO8MI6 h1jvkXOQJZPwZ2

Jong, M. S. Y., \& Tsai, C. C. (2016). Understanding the concerns of teachers about leveraging mobile technology to facilitate outdoor social inquiry learning: The EduVenture experience. Interactive Learning Environments, 24(2), 328-344. https://doi.org/10.1080/10494820.2015.1113710

Jung, I. (2005). ICT-pedagogy integration in teacher training: Application cases worldwide. Educational Technology \& Society, 8(2), 94-101. https://drive.google.com/open?id=1ftQrR7uk7EudKW7SofzZJOdqlOUd3blm

Kearney, M., \& Maher, D. (2019). Mobile learning in pre-service teacher education: Examining the use of professional learning networks. Australasian Journal of Educational Technology, 35(1), 135-148. https://doi.org/10.14742/ajet.4073

Kember, D. (1997). A reconceptualisation of the research into university academics' conceptions of teaching. Learning and Instruction, 7(3), 255-275. https://doi.org/10.1016/S0959-4752(96)00028-X

Klein, C., Lester, J., Rangwala, H., \& Johri, A. (2019). Technological barriers and incentives to learning analytics adoption in higher education: Insights from users. Journal of Computing in Higher Education, 31(3), 604-625. https://doi.org/10.1007/s12528-019-09210-5

Kopcha, T. J. (2012). Teachers' perceptions of the barriers to technology integration and practices with technology under situated professional development. Computers \& Education, 59(4), 1109-1121. https://doi.org/10.1016/j.compedu.2012.05.014

Laine, T. H., Sedano, C. A., Joy, M., \& Sutinen, E. (2010). Critical factors for technology integration in game-based pervasive learning spaces. IEEE Transactions on Learning Technologies, 3(4), 294-306. https://doi.org/10.1109/TLT.2010.16

Li, K. C., \& Wong, B. T. M. (2020). The use of student response systems with learning analytics: a review of case studies (2008-2017). International Journal of Mobile Learning and Organisation, 14(1), 63-79. https://doi.org/10.1504/IJMLO.2020.103901

Liu, C., Zowghi, D., Kearney, M., \& Bano, M. (2021). Inquiry-based mobile learning in secondary school science education: A systematic review. Journal of Computer Assisted Learning, 37(1), 1-23. https://doi.org/10.1111/jcal.12505

Livingston, K., \& Flores, M. A. (2017). Trends in teacher education: A review of papers published in the European journal of teacher education over 40 years. European Journal of Teacher Education, 40(5), 551-560. https://doi.org/10.1080/02619768.2017.1387970

Looi, C. K., Sun, D., \& Xie, W. (2015). Exploring students' progression in an inquiry science curriculum enabled by mobile learning. IEEE Transactions on Learning Technologies, 8(1), 43-54. https://doi.org/10.1109/tlt.2014.2376968

Louws, M. L., van Veen, K., Meirink, J. A., \& van Driel, J. H. (2017). Teachers' professional learning goals in relation to teaching experience. European Journal of Teacher Education, 40(4), 487-504. https://doi.org/10.1080/02619768.2017.1342241

Marton, F. (1981). Phenomenography-describing conceptions of the world around us. Instructional Science, 10(2), 177-200. https://doi.org/10.1007/BF00132516 
Mishra, P., \& Koehler, M. (2006). Technological pedagogical content knowledge: A framework for teacher knowledge. Teachers College Record, 108(6), 1017-1054.

https://www.tcrecord.org/content.asp?contentid=12516

Mueller, J., Wood, E., Willoughby, T., Ross, C., \& Specht, J. (2008). Identifying discriminating variables between teachers who fully integrate computers and teachers with limited integration. Computers \& Education, 51(4), 1523-1537. https://doi.org/10.1016/j.compedu.2008.02.003

O'Bannon, B. W., \& Thomas, K. (2014). Teacher perceptions of using mobile phones in the classroom: Age matters! Computers \& Education, 74, 15-25. https://doi.org/10.1016/j.compedu.2014.01.006

Pape, S. J., \& Prosser, S. K. (2018). Barriers to technology implementation in community college mathematics classrooms. Journal of Computing in Higher Education, 30(3), 620-636. https://doi.org/10.1007/s12528-018-9195-z

Prestridge, S. (2012). The beliefs behind the teacher that influences their ICT practices. Computers \& Education, 58(1), 449-458. https://doi.org/10.1016/j.compedu.2011.08.028

Primus, D. J., \& Sonnenburg, S. (2018). Flow experience in design thinking and practical synergies with Lego serious play. Creativity Research Journal, 30(1), 104-112. https://doi.org/10.1080/10400419.2018.1411574

Richardson, J. T. (1999). The concepts and methods of phenomenographic research. Review of Educational Research, 69(1), 53-82. https://doi.org/10.3102/00346543069001053

Sezer, B., \& Sezer, T. A. (2019). Teaching communication skills with technology: Creating a virtual patient for medical students. Australasian Journal of Educational Technology, 35(5), 183-198. https://doi.org/10.14742/ajet.4957

Taylor, D. L., \& Booth, S. (2015). Secondary physical science teachers' conceptions of science teaching in a context of change. International Journal of Science Education, 37(8), 1299-1320. https://doi.org/10.1080/09500693.2015.1035356

Teo, T., \& Zhou, M. (2017). The influence of teachers' conceptions of teaching and learning on their technology acceptance. Interactive Learning Environments, 25(4), 513-527. https://doi.org/10.1080/10494820.2016.1143844

Trigwell, K., Prosser, M., \& Taylor, P. (1994). Qualitative differences in approaches to teaching first year university science. Higher Education, 27(1), 75-84. https://doi.org/10.1007/BF01383761

Tsai, C. C. (2009). Conceptions of learning versus conceptions of web-based learning: The differences revealed by college students. Computers \& Education, 53(4), 1092-1103. https://doi.org/10.1016/j.compedu.2009.05.019

Tsai, C. C., \& Chai, C. S. (2012). The "third"-order barrier for technology-integration instruction: implications for teacher education. Australasian Journal of Educational Technology, 28(6), 10571060. https://doi.org/10.14742/ajet.810

Tseng, J. J., Lien, Y. J., \& Chen, H. J. (2016). Using a teacher support group to develop teacher knowledge of Mandarin teaching via web conferencing technology. Computer Assisted Language Learning, 29(1), 127-147. https://doi.org/10.1080/09588221.2014.903978

Uluyol, Ç., \& Şahin, S. (2016). Elementary school teachers' ICT use in the classroom and their motivators for using ICT. British Journal of Educational Technology, 47(1), 65-75. https://doi.org/10.1111/bjet.12220

Unger, K. L., \& Tracey, M. W. (2013). Examining the factors of a technology professional development intervention. Journal of Computing in Higher Education, 25(3), 123-146. https://doi.org/10.1007/s12528-013-9070-x

van Praag, B., \& Sanchez, H. S. (2015). Mobile technology in second language classrooms: Insights into its uses, pedagogical implications, and teacher beliefs. ReCALL, 27(3), 288-303. https://doi.org/10.1017/S0958344015000075

Wachira, P., \& Keengwe, J. (2011). Technology integration barriers: Urban school mathematics teachers' perspectives. Journal of Science Education and Technology, 20(1), 17-25. https://doi.org/10.1007/s10956-010-9230-y

Wang, S. K., Hsu, H. Y., Campbell, T., Coster, D. C., \& Longhurst, M. (2014). An investigation of middle school science teachers and students use of technology inside and outside of classrooms: Considering whether digital natives are more technology savvy than their teachers. Educational Technology Research and Development, 62(6), 637-662. https://doi.org/10.1007/s11423-014-9355-4

Wood, E., Mueller, J., Willoughby, T., Specht, J., \& Deyoung, T. (2005). Teachers' perceptions: Barriers and supports to using technology in the classroom. Education, Communication \& Information, 5(2), 183-206. https://doi.org/10.1080/14636310500186214 
Yang, Y. F., \& Tsai, C. C. (2010). Conceptions of and approaches to learning through online peer assessment. Learning and Instruction, 20(1), 72-83. https://doi.org/10.1016/j.learninstruc.2009.01.003

Yen, A. M. N. L. (2020). The influence of self-regulation processes on metacognition in a virtual learning environment. Educational Studies, 46(1), 1-17. https://doi.org/10.1080/03055698.2018.1516628

Corresponding author: Chin-Chung Tsai, tsaicc@ntnu.edu.tw

Copyright: Articles published in the Australasian Journal of Educational Technology (AJET) are available under Creative Commons Attribution Non-Commercial No Derivatives Licence (CC BYNC-ND 4.0). Authors retain copyright in their work and grant AJET right of first publication under CC BY-NC-ND 4.0.

Please cite as: Chen, C. H., Jong, M. S.-Y., \& Tsai. C. C. (2022). A comparison of in-service teachers' conceptions of barriers to mobile technology-integrated instruction and technology-integrated instruction. Australasian Journal of Educational Technology, 38(2), 35-50.

https://doi.org/10.14742/ajet.7299 